\title{
Ecologizing Knowledge: Considerations to Rethink Life in the Ever- Changing World Triggered by the Pandemic
}

By Dra Eliana Maria do Sacramento Soares \& Dra Andréia Morés

University of Caxias do Sul

Abstract- We present a theoretical essay approaching the question: according to which paradigm will we reorganize ourselves as a human society facing the experience of the Pandemic? To ecologize knowledges by articulating and establishing relations among different theories and forms of knowledge, we offer clues and possibilities to create forms of acting in life, especially in education practices, taking this moment we are living in as a trigger for transformations. In this way, we suggest the method of complexity as a strategy to redimension our way of understanding what we are living and transforming our way of acting. We emphasize the need of overcoming the current objectivism and rationalism, and proposing the systemic vision that includes the reflective, active, strategist subject as co-creator of the reality in which he lives. In this way, we suggest that educational practices need to be configured as a cognitive ecology, the result of the articulation of various contexts, coexistence scenarios, where teachers and students act together, taking care of each other and co-creating learning contexts in the experience. This approach can give rise to a form of education founded on a dynamic based on cooperating and sharing in circularity, surpassing control and judgment and enhancing the empowerment of being.

Keywords: ecology of knowledges; complexity; systemic vision; education practices; pandemic.

GJHSS-G Classification: FOR Code: 139999

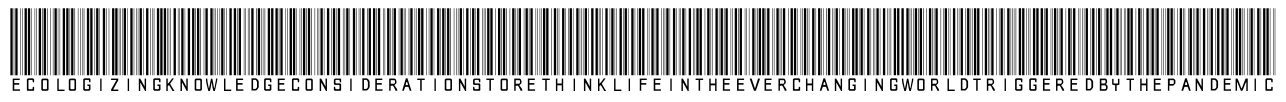

Strictly as per the compliance and regulations of:

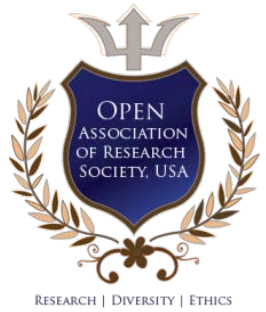

(C) 2021. Dra Eliana Maria do Sacramento Soares \& Dra Andréia Morés. This is a research/review paper, distributed under the terms of the Creative Commons Attribution-Noncommercial 3.0 Unported License http://creativecommons.org/licenses/by$\mathrm{nc} / 3.0 /$ ), permitting all non-commercial use, distribution, and reproduction in any medium, provided the original work is properly cited. 


\title{
Ecologizing Knowledge: Considerations to Rethink Life in the Ever-Changing World Triggered by the Pandemic
}

\author{
Dra Eliana Maria do Sacramento Soares ${ }^{\alpha} \&$ Dra Andréia Morés ${ }^{\sigma}$
}

Abstract- We present a theoretical essay approaching the question: according to which paradigm will we reorganize ourselves as a human society facing the experience of the Pandemic? To ecologize knowledges by articulating and establishing relations among different theories and forms of knowledge, we offer clues and possibilities to create forms of acting in life, especially in education practices, taking this moment we are living in as a trigger for transformations. In this way, we suggest the method of complexity as a strategy to redimension our way of understanding what we are living and transforming our way of acting. We emphasize the need of overcoming the current objectivism and rationalism, and proposing the systemic vision that includes the reflective, active, strategist subject as co-creator of the reality in which he lives. In this way, we suggest that educational practices need to be configured as a cognitive ecology, the result of the articulation of various contexts, coexistence scenarios, where teachers and students act together, taking care of each other and co-creating learning contexts in the experience. This approach can give rise to a form of education founded on a dynamic based on cooperating and sharing in circularity, surpassing control and judgment and enhancing the empowerment of being.

Keywords: ecology of knowledges; complexity; systemic vision; education practices; pandemic.

\section{InTRODUCTION}

$\mathrm{T}$ he planetary era referred to by Morin, Ciurana and Motta (2003) became evident in 2020, when humanity was taken over by the pandemic. This event made us reorganize our way of being in life very quickly, with social isolation being the great challenge from which several demands arose. All of this disturbed us. It caused us uncertainty. It caused us fears.

Morin (2005) states that situations that emerge within society come from the ways of being in the world and being of individuals, and proposes a path based on the understanding of human complexity trodden by selfanalysis, self-criticism and self-responsibility in order to understand and bring forth alternatives of overcoming limitations. From this perspective, these situations need to be understood from a systemic approach to enable the emergence of transformations.

Author a $\sigma$ : Professor and researcher of the Postgraduate Program, Master and Doctorate in Education, in the line of research, educational processes, language, technology and inclusion. University of Caxias do Sul,RS, Brazil.e-mails: emsoares@ucs.br, anmorees@ucs.br
Consistent with this idea, Moraes (2002) already emphasized that transformations are the result of processes triggered by disturbances, challenges or problems that stimulate the system to resize itself. Still Moraes (2008), discussing the adversities we live in, points out that they are fostered or mediated by crises of an ontological and anthropological nature. To these, we add the epistemological ones.

Thus, we start from the assumption that crises and adversities are opportunities to reorganize ourselves and understand the ecosystemic interrelations that involve us, in the sense of the interdependence between the environment, human actions and what we generate while living what we choose to live, even if we do it unconsciously. Moraes (2008) brings the ideas of David Böhm (1992), who recommends: "we need a global change of consciousness since we are political, social and historical beings" (p.18), so that we can make changes in the way society lives.

Santos (2020), approaching the subject of the pandemic, infers that it reveals the emptying of mediation among intellectuals, with regard to the production of their theorizations and the relationship of these with the claims and needs of citizens in their daily lives. He also points out that most intellectuals think and produce about the world, but do not think and produce with the world, with the needs that come from everyday life. To enter into these reflections, pervaded by the ecology of acquired knowledge, makes it possible to integrate the social commitment and the life of citizens into scientific work.

As the voices we evoke stated it, the world's society is faced with a great challenge. More than ever, the need for a method becomes evident; according to Morin, it should be a strategy to create new paths and ways of being in the world, which emerge in the erraticness and uncertainty in the transformation of the current experience. In this sense the "method is [...] what is used to learn and, at the same time, is learning itself. It is what allows us to know knowledge" (MORIN; CIURANA; MOTTA, 2003, p. 29) and so it is dynamic, recursive and dialogical: cause and effect, program and strategy built immersed in experience.

In view of these considerations, we prompt: from what paradigm are we going to reorganize as a 
human society in face of the experience of the Pandemic? Which method will we take?

In order to offer an answer to this question, we present this theoretical essay, which articulates ideas that we understand to contain concepts, clues and possibilities, to create new ways of acting in life, especially in the educational practices, having this moment that we live as a trigger of transformations.

To this end, we intend to ecologilize acquired knowledge in order to bring about principles to rethink and resize our living. The expression "ecology of acquired knowledge" refers to articulating and establishing relations between different theories and forms of knowledge from different cultures, understanding that these are the result of human experience in its different approaches and dimensions.

\section{IdeAs And Concepts from Which We DreW Inspiration to ECOlOGize}

The worldview based on the principles of scientific rationalism allowed for a technical-scientific development that bore important fruits for various sectors of society. Valuing the objective and external aspects of the experience more than the subjectivities of the individuals who live it, these principles may be not comprehensive enough to understand this phenomenon that pervades our society, the Pandemic arising from COVID 19.

It is important to realize that the human being, seeking to understand himself and his surroundings, builds theories based on the vision which he is able to express in each historical social / cultural / scientific moment. Thus, theoretical frameworks have emerged and the current one, in general, is based on determinism, stability and objectivity. At the same time that it enabled great scientific advancements, it also gave rise to several situations related to social inequality and ecological imbalance, facts that, among others, pervade the contemporary world.

We infer that we are observing a "turn", since the great challenges that Humanity faces today in diverse sectors (education, economy, health, human relations), aggravated and made evident by the Pandemic, need to be understood from a new viewpoint, which demands a new method to overcome them.

Studies related, primarily, to Quantum Physics and the discoveries of llya Prigogine, among others, based especially on the irreversibility of the laws of nature, indicate that living beings can be conceived as complex and unbalanced systems, acting on the edge of stability. These revelations lead us to recognize that uncertainty and instability are part of life's experiences, showing the complexity of the universe.

Santos (2008) also cites the contributions of Prigogine that refer to the emergence of systemic thinking, as well as of the concept of autopoiesis, highlighting the interactions between the phenomena we are currently experiencing and the possibilities of selforganization from oneself. Autopoieis (Maturana and Varela, 1997) refers to the constitutive dynamics of living beings, productive processes, where each component participates in the production and transformation of other elements of the network. Pellanda (2016), points out that human beings, through the use of consciousness and self-consciousness, can be producers of themselves, self-producing intertwined in living and knowing. Pellanda also argues that the autonomy of human beings is directly related to the mastery of themselves. According to this author:

"... this positioning leads us to look at/live/build reality and knowledge from other angles and attitudes... we are implicated observers. The challenge, therefore, is to make a path by walking, as the poet would say, transforming us at every step" (BOETTCHER; PELLANDA, 2010, p.49).

In order for us to act as implicated observers, co-creating with awareness the world we want to live in, we need to resize our beliefs, understand our context and how our actions create the experiences we experience.

In the intertwining of these ideas we find clues to walk a "new" path to interpret the world and our experience as human beings, considering systemic thinking, where the cosmos comes to be understood as a living and fully active system, in which different systems (social, political, environmental, family, school) are in constant harmony and interdependence. Systemic thinking challenges us to review our conceptions, our ways of living being and being in life, especially to understand what we are experiencing and to be able to act coherently.

Santos (2020), involved in the pandemic scenario, proposes some reflections in the context of social sciences and human sciences by questioning: "Does this mean that, at the beginning of the 21st century, the only way to avoid the ever-imminent ecological catastrophe is through the massive destruction of human life? Have we lost the preventive imagination and the political capacity to put it into practice?" (p. 07)

According to this author, all scientific-natural knowledge is scientific-social; all knowledge is local and total; all knowledge is self-knowledge; all scientific knowledge aims at constituting common sense. (Santos, 2008).

Thus, this author points out that there is an approximation between the scientific knowledge present in the natural sciences and the knowledge present in the social sciences, which in turn legitimize the overcoming of the dichotomy between these areas. If so, we can overcome fragmentation, disciplinarity, isolation 
between the various areas of knowledge, towards a broader vision.

This perspective makes it possible to understand that all scientific knowledge is selfknowledge, part of the subjects' knowledge, its acquired knowledge, linked to the course of personal and collective lives, articulated with the scientific studies. This understanding can be a reference for us to instrumentalize ourselves in times of crisis and challenges.

From this point of view, it is necessary to take scientific knowledge of systemic and complex view of life as an open system of knowledge, being in a continuous process of creation and renewal, in which the ecology of knowledge can be produced ecologically from different knowledge areas and its subjects, overcoming the unique vision of the dominant knowledge. Unscientific knowledge should be welcomed, be it Western or non-Western, popular or coming from minorities, valuing the interdependence between scientific and non-scientific knowledge (SANTOS, 2006).

This way of thinking can bring about a new balance, a new relationship between the various knowledges, so that this scenario will lead us to a full way of being together. For this movement welcomes voices, life and lived experiences of the subjects involved with and in community, in the sense that everyone acts in partnership and openness, in favor of plurality.

Pellanda (2016) refers to the paradigm of complexity as the theoretical framework with the potential to deal with the demands that instigate us, which the current paradigm is no longer able to cope with. She articulates the ideas of the paradigm of complexity with those of the theories developed by Gregory Bateson, Humberto Maturana, Francisco Varela and Spinoza, and others, to build his argumentative thread, focusing on the constitution of being.

From such approach, this researcher presents considerations and possibilities that refer to a recovery of human dimensions which include spirituality -banished during modernity on behalf of the priority to reason as well as in consequence of a deep fragmentation. In this way, according to her, we will be moving forward to put together what has been separated. In her argumentation she urges us to liten to the words of von Foerster (2003, p. 248) when he calls for an epistemology of "How we know, instead of What we know". This means asking ourselves in the face of this Pandemic: How we got here as implicated and cocreator subjects.

Following the thread of these reflections, Maturana and Dávila (2021), reflecting on the uncertainties and concerns we are living during the pandemic, sought to understand how we have created what we are living, and how this life in the pandemic teaches us to "harvest" new dynamics to transform the ways of being and living in human experience. They invite us to make a transformation in the way of thinking and living in order to create a future based on collaborative actions, coexistence and mutual respect.

These authors emphasize that the pandemic has revealed to us several other diseases of our society, both biological and social and cultural diseases, highlighting inequality, exclusions, disputes; the accumulation of many to the detriment of the majority; disrespect to our Planet, suffering and fragmentation of the subject who lives unaware and disconnected from one's own self.

The invitation of Maturana and Dávila (2021) is to reflect on how we lived before the pandemic, understanding the criteria and choices that we have made and that have brought us to this moment, taking this scenario that worries us as an opportunity to awaken our consciousness. To this end, they propose "a reflective understanding", of what we live and create with our living, expanding our vision to act coherently at this crucial moment for us humans and for our planet.

In this sense, we include the concept of psychic eras (Maturana and Dávila, 2009) to understand the choices that brought us to this point, and realize that, just as humanity has made these choices, we can now choose what we will accomplish.

Psychic eras (Maturana and Dávila, 2009, p. 30), "configurations of the emotion of everyday living that [...] characterize distinct moments of human history." Thus feelings, desires, emotions and our choices emerge as psychic dimensions arising from consciousness, comprehension and understanding, so that our biological-cultural matrix is the foundation of all our feeling and doing, being and living.

With this viewpoint, the authors propose six psychic eras and present the respective emotions and doings that define them, as well as their processes of emergence and extinction and/or transformation.

Therefore, the challenge we have in this historic moment is to seriously and self-responsibility answer questions like "How are we doing what we are doing?" and "How are we generating so much pain and suffering for ourselves and for others?" We can take the Pandemic as the trigger of a new cycle co-created by all of us.

Competition or collaboration? How to live together in human society?

We are at a turning point of human experience on Earth: What alternatives do we have to choose? What do we want to keep? What do we want to transform? What to leave to our children and descendants?

The voices we have brought in this text along with ours claim: It takes a new way of thinking to understand what we are living and build a new route: 
systemic thinking and the principles of complexity as a method and path. We need to build together, in partnership and side-by-side, in order to bring about, in the sense of co-creating, the experiences that will lead us to the transformation we long for.

\section{ili. Developments and Recommendations}

Resuming the focus of our essay and considering the ideas that we present, we offer paths, clues and procedures to create new ways of being and living in human experience in a post-pandemic moment. We emphasize that the considerations that we present are ruled by processes, relations and significations that we have been giving to the voices of the subjects we intend to articulate, in the sense of ecologizing knowledge and thinking about possibilities to act in the after pandemic scene.

Thus, we propose as a strategy to resize and transform our living, based on the challenges and uncertainties of the current moment, the method of complexity, which is founded on the principles of this approach according to Morin; Ciurana; Motta, (2003). This principles are, namely: systemic; holographic; retroactivity; recursion; autonomy/ dependency; dialogical; reintroduction of the knowing subject in the process of knowing. The latter emphasizes the overcoming of objectivism, assuming the subject as thinking, reflective, active, influential, strategist, in short, co-creator of reality. Consequently, both knowing and living come to be understood not as an accumulation of information and facts, but as an emergence of the action of subjects who interpret, in uncertainty, in the social and scientific context, and create ways of dealing with experiences.

For human relations in their various aspects and contexts, we invite each being to look at oneself, in a process of being with oneself, and seeking personal empowerment in order to, from one's entirety, be with the other. This leads to a path of self-knowledge where the observation of oneself in a metacognitive and empowering attitude (Boettcher and Pellanda, 2010) can lead to personal transformation. And so, beings can act in everyday life in another way, allowing collaborative and co-inspirational relationships with mutual respect to emerge.

We infer that procedures based on listening to oneself, in recognizing knowledge and acquired knowledge, in systemic articulation, can allow the development of new ways of being with the participation of different subjects. Thus, according to Santos (2006, p. 158): "The ecology of knowledges has to be produced ecologically with the participation of different knowledges and their subjects". In this way, encompassing in the ecology of knowledges the perspectives of the citizens, life in society, collectivity, self-knowledge and the plurality present in planetary life.
The reflections and criticisms proposed by the authors in question, in their different works, suggest a vision that advances to the dimension of Sciences, of knowledge, of epistemological plurality. The plural epistemologies of scientific practices refer to other scientific knowledge, overcoming the vision of a single knowledge, which are translated into new configurations of knowledge.

In the context of educational practices, teachers and students can (re)connect with their capacity for reorganization, acting on their way of living in a creative and empowering way, allowing the constitution of belonging, interacting in experiences characterized by the acceptance of the other, by mutual respect, suspension of judgment, by the acceptance of difference, by the presence without exigence, and other forms of being together in legitimacy.

For this to happen, it is necessary to recognize multi-referentiality, since the entire educational process is subject to different interpretations and to plurality of views and knowledges.

This path suggests that the network of the educational process can be configured as a cognitive ecology that emerges from the various systems that act in the educational processes in the context of the digital and hybrid culture that we are experiencing. Lévy (1993) takes this expression to represent the individual and collective subjectivation processes that were acting and continue to act as a result of contemporary culture. This author explains that these processes happen due to complexification and displacement of the aspects involved.

Thus, we can think of a learning ecology as something that emerges from the articulation between the various contexts of educational practice: cognitive, social, emotional, and others.

The ecology of learning can be understood as the articulation of various contexts, scenarios of coexistence, where teachers and students act together, taking care of each other and co-creating, with mutual respect and responsibility. This is a plane in which educational strategies and interventions are based on flows and relationships, so that the subjects are implicated observers of their actions and that learning emerges supported by conversational networks that coordinate the doing and being of the participants. Living in this domain of action, the subjects accept each other and modify themselves as legitimate in the singularity of coexistence. It follows that educating becomes a dynamic of cooperating and sharing in circularity, surpassing control and judgment and enhancing the empowerment of being.

The coexistence referred to here refers to being together in connection, accepting the other as a legitimate individual in dignity and legitimacy, which defines the emotion of love, which, together with 
cooperation, are considered biological constituents of our species. Maturana (1998, p. 23) asserts that "love is the emotion that constitutes the domain of behaviors in which the acceptance of the other as a legitimate other in coexistence occurs". Thus, this author places the emotion of loving in the social ground of coexistence. And he emphasizes that coexistence based on competition and individualism does not constitute a social space, because, by denying the other, we deny his options of being and doing. So, to accept others is to legitimize their personal life projects. It means being entirely in coexistence, it is living the present along with the other. And by being present with the other, being with oneself as a whole.

When proposing a transformation for educational practices, based on learning to live together, we agree with Maturana (2002) when he affirms that education is a phenomenon of transformation while living together, in a relational context. Talking about a relationship means transcending fragmentation. Looking at educational practices, school culture and teacher/student training from this perspective, can be an alternative that goes beyond the idea that we are separated from what we do and what happens to us. This means understanding the human being, in the context of these practices, intertwined with the other and in conjunction with one's domain of action.

In this line of understanding, educational practice is a transformative action, based on the coordination of recursive actions, surpassing control and judgment (MATURANA and DÁVILA, 2009). Santos (2019) refers to transformative education as the element which fosters a critical spirit and can lead the subject to develop a critical and argumentative look considering different opinions and approaches. Therefore, the educational practice embraces the human, the social, the life, the citizen, combining different voices, experiences, and life experiences.

We emphasize that the practices that we create and will still create as human beings constitute a record of recursive operations, which make our experiences emerge and cause structural changes, which are manifested in the ways of acting, interacting, living together, and thinking. From this focus, we propose to take the experience we are living as a trigger point for redimensioning the dynamics of our lives and social relationships, in order to transform our action in the world, toward ourselves and towards the others. We know that, given what we have considered in the reflections hereby presented, nothing will be given from outside of ourselves, from outside of our lives, from our Planet. We, human beings, need to empower ourselves and make emerge what we choose.

\section{References Références Referencias}

1. BOETTCHER, D. M.; PELLANDA, N.M.C. (org). Vivências autopoiéticas. Santa Cruz do Sul: Edunisc, 2010.

2. BÖHM, D. A totalidade e a ordem implicada. Uma nova percepção da realidade. São Paulo: Cultrix, 1992.

3. FOERSTER, Von Heinz. Understanding, understanding. New York: Spring, 2003.

4. LÉVY, P. As tecnologias da inteligência. O futuro do pensamento na era da informática. Rio de Janeiro: Editora 34, 1993.

5. MATURANA, H.; D'AVILA, X. La revolución reflexiva. Una invitacion a crear un futuro de colaboratión. Editorial Planeta Chilena S. A.: Previdencia, Santiago do Chile, 2021.

6. MATURANA, H.; DÁVILA, X. Habitar humano em seis ensaios de biologia-cultural. São Paulo: Palas Athena, 2009.

7. MATURANA, H.; VARELA, F. J. G. De máquinas e seres vivos: autopoiese - a organização do vivo. Porto Alegre: Artes Médicas, 1997.

8. MATURANA, H. R. Transformación en la convivencia. Santiago do Chile: Dolmen Ediciones, 2002.

9. MATURANA, H. R. Emoções e linguagem na educação e na política. Belo Horizonte: Ed. UFMG, 1998.

10. MORAES, M. C. Ecologia dos saberes: complexidade, transdisciplinaridade e educação. São Paulo: Antakarana/WHH - Willis Harman House, 2008.

11. MORAES, M. C. Tecendo a rede, mas com que paradigma? In: MORAES, M. C. (Org.). Educação a distância: fundamentos e práticas. Campinas: UNICAMP/NIED, 2002.

12. MORIN, E.; CIURANA E.; MOTTA, R. D. Educar na era planetária: o pensamento complexo como método de aprendizagem no erro e na incerteza humana. São Paulo: Ed. Cortez, 2003.

13. MORIN, E. Ciência com consciência. Rio de Janeiro: Bertrand, Brasil, 2005.

14. PELLANDA, N. M. C. Complexidade e invenção de si: rumo a uma integração cósmica. In: $\mathrm{RECH}$, J.; SACRAMENTO SOARES, E. M. Educação e Espiritualidade: Tessituras para Construção de uma Cultura de Paz. EDUCS, Caxias do Sul, RS, 2016.

15. Disponível em https://www.ucs.br/educs/livro/ educacao-e-espiritualidade-tessituras-paraconstrucao-de-uma-cultura-de-paz/ Access in: 06 maio 2021.

16. SANTOS, B. de S. A Cruel Pedagogia do Vírus. Coimbra: Edições Almedina, S.A. 2020.

17. SANTOS, B. de S. Ecologia de Saberes. Revista PUCRS. No 190 |Julho/Setembro 2019. Disponível 
em: $\quad<$ https://www.pucrs.br/revista/ecologia-desaberes/>. Access in: 25 mar. 2021.

18. SANTOS, B. de S. Um discurso sobre as ciências. 5. ed. São Paulo: Cortez, 2008.

19. SANTOS, B. de S. Conhecimento prudente para uma vida decente: Um discurso sobre as ciências revisitado. 2.ed. São Paulo: Cortez, 2006. 